\title{
Romanticizing differences and managing diversities: a perspective on harmonization, language policy, and planning
}

\author{
Sinfree Makoni ${ }^{1}$
}

Published online: 14 July 2015

(C) Springer Science+Business Media Dordrecht 2015

\section{Preamble}

Harmonization and other sociolinguistic variants (e.g., unification, soft harmonization, natural harmonization, core, and cluster) are metaphors that describe a series of interlocking metalinguistic processes through which common vocabulary or structure for a putative language is created. Metalinguistic processes are neither historically new nor restricted to Africa. Even though harmonization is situated in this special issue in African contexts (with the exception of one paper on China), five key principles arise whose relevance resonates beyond historical and contemporary Africa: (1) community participation in harmonization projects, (2) the role and status of harmonization as a strategy to facilitate social equality, (3) management of diversity, (4) harmonization and the development of epistemology of African languages, and (5) the adequacy of harmonization as a method of historical analysis.

First, it is plausible to argue that harmonization projects are likely to fail if communities do not participate actively in such projects. While this may be true, the converse does not necessarily always apply. In other words, community involvement in harmonization and related projects does not necessarily guarantee the success of such projects (Dobrin 2008). Second, while one of the most powerful arguments supporting harmonization is the benefits of language development, it does not necessarily result in social equality. In some cases, paradoxically, it may even accentuate differences within communities. Third, harmonization creates intellectual opportunities to manage diversity, serving as an important counterpoint

Sinfree Makoni

sbm12@psu.edu

1 Department of Applied Linguistics and program in African Studies, Penn State University, State College, PA 16801, USA 
to a romantic celebration of diversity apparent in some African sociolinguistic projects. Diversity in harmonization is construed as problematic. Fourth, harmonization provides opportunities to explore the relationship between language and epistemology. By tracing the discursive trajectories of philosophies and metaphors about language, harmonization creates an intellectual space that renders it feasible to outline the development of philosophical thoughts in African sociolinguistics. Fifth, because of a "linguistic turn" in African history, harmonization, as a form of linguistic analysis, is a form of historical practice. Harmonization's effectiveness as a method of historical study, inter-alia, is one of the primary issues addressed in this special issue.

In light of the above introduction, I explore the implications of harmonization for language policy, history, and philosophy in Africa using Zimbabwe, South Africa, Sudan, and Senegal as case studies. In these case studies, I draw upon a diverse range of materials, including language reports, controversies among African intellectuals in local African newspapers, and academic material on the topic. I conclude this introductory essay with a brief description of the articles in this special collection and the ways their contributions substantiate the complex relationship among harmonization, politics of language, and language policies in Africa. Specifically, I address the following questions and organize my introduction around them:

1. What is the relationship between harmonization and unification, and what are the implications of that relationship for language policy?

2. What is the relationship between harmonization and standardization, and what are the implications of that relationship for language policy?

3. What is the relationship between harmonization and individual and social identities, and what are its implications for language policy?

4. What is the role of language academies and the State in promoting harmonization, and what are implications of such politics for language policy?

5. What is the nature of community participation in development of indigenous languages?

\section{Harmonization, unification, and language policy}

The term harmonization was rarely used in colonial linguistics but was foreshadowed by the term unification. While both terms may be considered semantically identical, they are ideologically different. Unification of African languages as a discourse strategy is part of the universe of colonialism or a form of "vernacularconstruction" in terms of colonial discourses, while harmonization is part of a discourse that seeks to contain and reverse the effects of colonialism's legacy. Unification and harmonization, therefore, have different ideological and discursive statuses, histories, and trajectories in African sociolinguistic thought. The degree to which harmonization succeeds in containing the legacy of colonialism is a moot question, as I illustrate in this introduction. 
The unification of African languages or dialects entailed "aligning" different orthographies, integrating multiple orthographies, or establishing common linguistic features. The most well-known examples of harmonization is the unification of Shona dialects (Doke 1931) and Union Igbo. Another meaning of harmonization is the one associated with Prah (2008) in which harmonization is defined as made up of combining dialects into mutually understood languages or clustering dialects into 12 mutually understood (written) languages.

Unification of languages or dialects is apparently aimed to produce "economies of scale," which will make producing material in African languages attractive to publishers, thereby enhancing literacy in those languages. In the colonial period, unification was construed as both a linguistic and political project. For example, the unification of Shona dialects can be taken as a strategy to facilitate colonial administration and control of Africans. The ways in which the social and linguistic aspects of linguistic unification and harmonization were realized differed, depending upon the dynamics and politics of each context. In light of these dynamics, I have opted to illustrate my argument using a number of case studies: Zimbabwe, South Africa, Sudan, and Senegal.

\section{Colonial Rhodesia and the unification of Shona}

Colonial Rhodesia aptly illustrates issues about the "unification of Shona dialects" (Doke 1931) and the role of individual linguists, missionaries, and the colonial state in facilitating unification. The title of the Doke (1931) report, Report on the Unification of the Shona Dialects, suggests that the dialects were being unified, not the languages themselves (if such a distinction is epistemologically possible). The Doke report is an excellent example of colonial government intervention into African sociolinguistics in Rhodesia. In the report, it is made clear that these efforts were "carried out under the auspices of the Government of Southern Rhodesia and the Carnegie Corporation" and were presented to the Colonial Rhodesia Legislative Assembly in 1931 (Doke 1931). The fact that unification was sponsored by the Southern Rhodesian government reflects its institutional status and its relevance as one of the instruments used by the colonial government not only to manage but also to constrain diversity. That the project was also funded partly by the Carnegie Corporation (CC) is also significant because the CC was supposedly a philanthropic organization seeking to fund research and improve social advancement in Canada and then-British colonies. However, this objective was broad enough to include projects such as the Doke report that appear to improve the welfare of Africans immediately or in the long term. The CC's funding of the Doke report reflects the complex relations between colonialism, on the one hand, and philanthropic concerns with colonialism, on the other.

In the table of the contents of Doke's (1931) report, the metalanguage about language is imprecise and used inconsistently. For example, reference is made to "language-groups" and "dialects": the Zezuru, Karanga, and Manyika languagegroups. Surprisingly, the terminology changes from pages 119-135 of the report, where there is a shift to Manyika or Zezuru. At a conceptual level, the indeterminacy 
in the use of the categories "group," "language," and "dialect" in a report, which has significant importance in the discursive history of Shona, reflects inconsistency and ideological conflicts. The term Shona union is, at times, used alternatively with union Shona, masking tensions within colonial discourses about language practices encapsulated in terms such as "language-group," "language," and "dialects." This inconsistency is not peculiar to colonial missionary encounters but also recurs in other reports and in radical postcolonial African scholarship on language harmonization. The inconsistency and widespread nature of the terms relating to harmonization are apparent in the use of alternative and perhaps conflicting terms such as "soft harmonization," "natural harmonization," "core languages," and "language clusters." The inconsistency and multiple uses of categories render it difficult to navigate both colonial and postcolonial scholarship on harmonization. Regardless of how the terms were used, they had clear social impact and influenced colonial and postcolonial elite/nationalist government to manage and organize African communities.

In Rhodesia, there were a number of different missionaries, including Anglican, Dutch, and American. Each missionary station developed its version of Latinate orthography and spelling in the late twentieth and early twenty first centuries. In some cases, Rhodesian orthographies were modeled on those from other geographical regions, particularly East Africa. In rare cases, individual missionaries invented their own orthographies, a situation that was not peculiar to Rhodesia/ Zimbabwe. The illustration below captures the relationship between different missionaries and geographical regions from which they operated and sub-ethnicities in which they were located:

Zezuru Roman Catholic Church and Wesleyan Methodist Church

Ndau American Board Mission and American Methodist

ChiManyika Anglican

Kalanga London Missionary Society

Karanga Dutch Reformed Church

In such cases, unionization of languages was prompted by a standard language ideology that sought to establish uniformity over variation, the underlying assumption being that diversity has to be managed and unionization was implemented as a diversity management strategy. Paradoxically, unification or creation of standardized languages enhanced sociolinguistic diversity in speech practices. The varieties that formed the basis on which the orthographies were produced were versions of Shona or African languages spoken by missionaries and referred to as (chibaba) in colonial Rhodesia. Missionary speakers of chibaba were second language speakers of African languages and, therefore, bilingual. In simple terms, the orthographies produced were solely based on Europeanized varieties of African languages. Yet chibaba was widely used when it was subsequently framed as an indigenous language and used as a medium of instruction in schools. Chibaba and union Shona contributed to the emergence of a diaglossic situation that might not have existed prior to African/missionary encounters. While missionary engagement with Rhodesia enhanced linguistic diversity, it also limited it. The 
construction of African grammars for individual dialects reduced the diversity within African communities because diverse languages were described using the same template that, ultimately, was drawn from Latin. However, the chibaba example shows that Europeans were 'authorities' in a development of orthographies, coining terms, compiling dictionaries and grammars, translating books in particular the Bible.

\section{Identities and wars over diacritics}

In Rhodesia, early efforts to address perceived problems arising from orthographic variation were addressed at a religious conference in 1909. Efforts to create a written standard orthography (i.e., to harmonize different orthographies) did not succeed because of differences between religious denominations about which orthography to adopt. Each denomination identified intensely with its own orthography and felt that selecting a single orthography or integrating them was impossible. Put differently, there was tension between standardization and variation; similar conflicts occurred in other contexts as well.

After the failure of the 1909 religious conference to create a union Shona, Doke, a linguist from Witwatersrand, was tasked with standardizing Shona. He based his integration of Shona largely on Manyika and chiZezuru, excluding other dialects such as Ndau and Kalanga. The latter was assigned as a dialect to another language: Ndebele spoken in Southwestern Zimbabwe. Phonetic and phonological properties and a major component of chiNdau were also excluded from union Shona. At a lexical and idiomatic level, union Shona was based largely on chiZezuru, which de facto approximated closely union Shona. Since chiNdau speakers and Kalanga speakers did not constitute a major basis for the construction of union Shona, speakers of those dialects could be construed as having been discriminated against.

Another important consequence of the Rejaf (Abdelhay et al. 2013) conference that had long-term effects was the exclusion of Arabic as a medium of instruction in south Sudan, thus enhancing the image of a Christian/English/African South, as opposed to an Arab/Islamic North. The 1929 Rejaf conference was the third to address issues about language in education and orthographies for the Sudan and Northern Uganda. Ongoing conferences in 1918, 1927, and 1929 (the Rejaf conference) were designed to address language in southern Sudan (Miner 2003).

The Rejaf conference was attended by representatives from different African colonies, such as Uganda and the Belgian Congo. It was chaired by M. M. J. Matthew, then Secretary for Education and Health in the Sudan; delegates from six different missions; and Westermann, an expert in linguistics who had studied Shilluk, a language spoken in Southern Sudan. The conference was instructed to achieve the following:

1. To make recommendations as to whether a system of group languages could be selected as a medium of instruction.

2. To explore the possibility of a unified system of orthography (emphasis mine). 
3. To explore cooperation in textbook production and the developments of templates for a "skeleton grammar," reading books, and primers that would facilitate standardization of the curriculum across language groups.

Even though most of the deliberations about creating a unified system of orthography took place without any substantial input from Africans, a "close reading" of Westermann reflects tensions between designing orthographies that would serve the interests of Europeans and those systems that would serve the interests of Africans:

The script we want to introduce is intended for use by Africans, not for use by Europeans who want to learn the language. We should keep this constantly in mind. It means that we should try to look at the problems from the African's point of view, not from our own. His difficulties are not always ours; we are to remember that our views on orthography are hopelessly restricted by the history of orthography of our European languages. (Westermann in Rejaf 1928, pp. 14-15, as cited in Miner 2003)

Westermann (1928, as cited in Miner 2003) makes an apt point when he draws attention to the absence of African voices in conferences, even those addressing issues that would have a substantial impact on their sociolinguistic, educational, and political lives. There were, however, no monolithic missionary/colonial voices, as the Westermann quotation above expresses. Similarly, even when Africans were engaged in sociolinguistic issues, there was no monolithic African voice on issues relating to language harmonization. The multiplicity of missionary/colonial voices and African voices complicated relationships between colonialism and African resistance, and the nature of the politics of each participant cannot be easily read from the position they adopted toward issues about language in language policy. Ironically, even when Africans, largely African elites, were involved, sharp and, at times, acrimonious controversies arose. For example, the Nhlapo-Rabaroko debate in South Africa during the apartheid regime reflects the degree and extent to which there was no monolithic African voice on harmonization of African languages and its suitability as an instrument of language policy.

\section{The Nhlapo proposal and recurring controversies about harmonization}

Nhlapo (1953) is well known in southern African sociolinguistics literature for his proposal to unify Nguni languages, on the one hand, and Sotho languages, on the other. The proposal generated acute controversy and acrimonious debate led by Raboroko (1953). Jacob Nhlapo (also affectionately referred to as "Dr. Degrees" by his friends and acquaintances because of the many degrees he had either acquired or had conferred on him) is well known for his contribution to language policy, particularly his proposal that all major languages be systematically combined into a single language, "the throwing of Bantu languages into one pot" in the 1944 pamphlet Bantu Babel: Will the Bantu Language Live? Nhlapo argued excitedly that Xhosa, Zulu, and other intermediate languages such as Swazi and Ndebele be made 
into one language: “...People who speak or write Xhosaised Zulu and Zuluised Xhosa should be encouraged and not condemned. They are forerunners to the harmonized Nguni languages" (Nhlapo, n.d.). Nhlapo (1953) elaborated his argument about the unification of Nguni languages in a short essay entitled 'The Linguistic Revolution' in the monthly magazine Liberation in August 1953.

The essay elicited vicious reaction by Raboroko (1953) in the September 1953 issue of Liberation. Raboroko described Nhlapo's proposal of throwing Bantu languages into one pot as "preposterous and impracticable." The Nhlapo/Raboroko debate and the intellectual history of South Africa, when compared with that of Shona in Zimbabwe, demonstrate the extent to which the same sociolinguistic situation may yield different outcomes. For example, Shona was regarded as a continuum, while in South Africa, the policies produced speech forms that were construed as different languages.

The idea of harmonization generated controversies even in post-apartheid South Africa when it was revived by Neville Alexander, who proposed that it become the basis of language policy in South Africa. The underlying assumption in Nhlapo/ Neville Alexander (see Heugh, this volume) seems to be that language diversity is impracticable as a site of language policy; diversity needed to be managed. Harmonization would reduce the extent of diversity, rendering the policies much more manageable. Nhlapo, and to some extent Alexander, seem to have been concentrating on language as a system - as forms that can be integrated.

The response by Sizwe Satyo, a specialist in African languages at the University of Cape Town, to Nhlapo/Alexander at the University of Cape Town is indicative of the challenges African scholars faced regarding issues about harmonization and the challenges that diversity poses for the framework. Satyo proposed a much more watered-down version of harmonization that he referred to as "soft harmonization." For Satyo, it was not necessary to develop and harmonize African languages because the processes of harmonization had already taken place, rendering efforts to harmonize them unnecessary. If harmonization had to take place, Satyo argued, it had to be a bottom-up policy, unlike that proposed by Nhlapo/Alexander. In both proposals, the voices and participation of local communities are erased from view. Arguably, however, local communities played a more significant role in "soft harmonization" because the objective was to describe language practices as they were-forms of "pan-ethnic vernaculars"-and not as idealized artifacts, as in the Nhlapo/Alexander framework.

\section{Arabic, indigenous orthography and Latin alphabet: the case of Senegal}

In African scholarship, there has been a general conviction of the cognitive and social benefits of using indigenous African languages in literacy and schooling. The case of Senegal compels us to adopt a much more nuanced view of this argument. In most cases, indigenous refers to language, not locally created orthographies, as the Senegalese case illustrates. In Senegal, the Mande and Nko were literate using Nko orthography indigenous to Senegal. Between 1958 and 1968, sharp controversies arose about orthography: whether to use Ajami (an Arab-based orthography), a Latin 
orthography, or indigenous orthography in Senegal. Two other idiosyncratic scripts, as pointed out earlier, were constructed and disseminated by a tailor and a selftaught Arabist. One of the most powerful arguments for the use of Ajami was that a relatively large number of Senegalese were literate in a variety of Ajami that had been adapted to the Wolof, Pulaar, and Mandingo languages. A relatively small minority of Senegalese learn to read and write in French; from such a perspective, one would have imagined that Ajami and not a Latinate-based orthography would have been used.

Contrary to expectations, a national language policy was proclaimed in support of a Latinate based orthography. Issues about orthography were so socially divisive that the Senegalese Supreme Court had to intervene. Such sharp controversies arose over the use of diagraphs that their use was subsequently determined by the Senegalese Supreme Court Decree No. 71,566 of May 1971, which adopted the "one letter for one sound" principle for the six Senegalese languages. The Senegalese Supreme Court's intervention and ruling in favor of the "one letter one sound" principle reflects its beliefs about the importance of standardization as a primary feature of language. The "one letter one sound" policy and the use of a Latinate orthography did not, however, change or affect actual writing practices because the writing of some Senegalese drew bits and pieces from different orthographies. The Senegalese case illustrates the degree to which language policy pronouncements are, at times, aimed at unscrambling writing practices and producing idealized forms of writing wherein only one orthography is used at a time, not a combination of different orthographies. From a Senegalese perspective, harmonized practices were interpreted as problematic, while, in other contexts, the absence of harmonization was a source of problems, as the Pan Africanist perspective discussed below shows.

\section{Pan African approaches to harmonization}

While most of the projects on language unification and harmonization that I have discussed so far dealt with specific countries or regions, the "harmonization project" led by Ghanaian sociologist Kwesi Prah was much more ambitious. PanAfrican in scope insofar as it attempted to describe and outline principles along which harmonization may be developed in Africa, this project, on which Prah has been working for the last quarter century, was prompted by the need to develop policies and literacy materials that could be widely used across different polities of the African continent. Extensive usage of literacy materials was limited by the linguistic diversity within Africa. Prah (2008) argued that among 600-700 million Africans, 80-85 \% speak 15-17 “core" languages either as first, second, or third languages. An example of a language "cluster" can be illustrated by Gbe/Ewespeaking peoples, who can be found along the West African coast from Ghana, Togo, Benin, and the Nigerian border. The cluster includes Aja in Badagara/Nigeria, Aja and Mina.fon in Benin, Mina and Ewe in Togo, and Ewe in Ghana (Prah 2008). Another example that easily forms a cluster is Ndebele speakers, who can be found in South Africa, Botswana, Lesotho, Swaziland, and Zimbabwe. The presence of a 
limited number of "core" languages makes introduction of literacy much easier, and perhaps the fewer languages spoken by relatively large numbers of people makes producing literacy material more attractive to publishers than producing written materials that are used by a small number of people. Kwesi Prah deserves credit for his harmonization project and his proposition for rendering diversity in Africa manageable and beneficial to Africans and perhaps more economically attractive to publishers.

Because of the importance of Prah's project, it is necessary to evaluate some of the main principles on which it is founded. While Prah might be correct about the number of core languages and the percentages of Africans who speak them, how he arrived at the figures he treats as factual is not empirically self-evident. Efforts to establish common principles of mutual intelligibility are important insofar as they attempt to build consistency in measuring intelligibility; thus, it behooves him to explain theoretically why he arrived at an $80 \%$ cutoff point. Another primary theoretical advantage of Prah's project is how he uses the same framework and instrumentation in different contexts. The use of the same instruments gives the project a high degree of reliability, but unfortunately, the sociolinguistic validity of the project becomes suspect because the methodology does not seem to be sensitive to context. As a result, he ends up in a situation that he may not have found productive: a one-size-fits-all approach. Prah is clearly writing from a managerial position in which counting and innumerability are critically important. The identification either of core languages or dialects that can be made into clusters is conceivable if one subscribes to the positivistic assumption that languages are external and independent of their users. The concepts of "core" and cluster are "akin" to the metaphor of languages, which, like the former, tries to capture the nature of the relationships between languages. The difference, however, is that Prah postulates social relationships between languages while the family metaphor biologizes relationships between languages.

\section{Reflections}

In this special issue, I have explored the nature of the construct of harmonization by situating it within different historical and contemporary contexts, ranging from late $19^{\text {th }}$ century Sudan to contemporary Chinese feelings about harmonization. In the issue, it was apparent that harmonization could be used both to serve issues about "governmentality" (Foucault 1978/1982, p. 43) during colonial rule and, at times, to mitigate the effects of colonialism. The analysis, however, also illustrated that there are no uniform and monological voices about the value and significance of harmonization, either during the colonial era or in postcolonial Africa. Harmonization has been proposed as a way to accomplish many language planning objectives. In some cases, such as the formation of union Igbo and union Shona (also referred to as Shona union), which were legislated in the ninetieth and early twentieth centuries, the long-term effects of the formation or birth of the languages are real and apparent, as captured in language materials and tests. In other cases, such as 
Kwesi Prah's project, it is still too early to be fully aware of the impact because such projects vary in their uptake.

In spite of these factors, one major intellectual theme runs through most of these projects. The emphasis has been on the role and status of African languages within African languages (i.e., whether, African languages were to be theoretically amalgamated or kept as separate entities) and not in relationship to European languages. There is, contrary to expectations, very limited preoccupation with multilingualism. The closest reference to bilingualism is when Raboroko (1953) in his response to Jacob Nhlapo (1953) argues for the importance of bilingualism. The bilingualism he had in mind, however, was between African languages (e.g., Xhosa and Swahili). The issue in this case is not the practicality of using Swahili as a second language in southern African contexts but, rather, that English is erased from such discussion and is, thus, discursively constructed as irrelevant. The issue is not whether European languages would serve as national languages or whether the rights of African languages have to be maintained or advocated for. The issue that preoccupied most harmonizationists as analysts or practitioners was how to manage diversity, which, at times, was construed as negative, as illustrated in the following quotation from Nhlapo reference

When the question of reducing Ibo in Nigeria to writing, the multiplicity of its dialects reared its head. Each tribal group wished to have its dialect written. The writer in the language decided on "Union Ibo" which was a fusing of the various dialects whose vocabularies became contributions to the combined language. Union Ibo was taught in schools and was used in the translation of the Bible.

One of the primary critiques of harmonization projects is the lack of robust community involvement in them. While this argument is clearly welcome, the converse does not necessarily apply. In other words, community involvement in issues directly affecting them does not necessarily result in successful uptake of the projects in the long term. From a Western perspective, the lack or withdrawal of outside expertise and involvement might be regarded as valuable because it shows respect for a community's autonomy. However, in some cases, that community may construe withdrawal from the projects as lack of commitment to a project that outsiders themselves have initially set up and in which the communities might not have had any strong interest in the beginning, as Bashkow (2006) observed with Papua New Guinea:

While well-meaning westerners are intensely concerned to respect the dignityimplying autonomy-of people they see as poor or subaltern, Papua New Guineans often interprets westerners' hesitancy to involve themselves in their affairs as disdainful aloofness, one that leads people to draw negative inferences about their own moral worth. (Bashkow 2006, as cited in Dobrin 2008, p. 307)

Bashkow's observation raises some skepticism of statements such as the following, which have tended to be regarded as axiomatic: 
It is only if indigenous speech community itself desires and initiates efforts toward language survival that such programs should exist or would have any chance of success. (Hinton 2001, p. 5, as cited in Dobrin 2008, p. 303)

Only the indigenous community itself can save its language. (Crystal 2000, p. 111, as cited in Dobrin 2008, p. 303)

The overall success of any revitalization program depends on the motivation of the future speakers and community which supports them. (Grenoble and Whaley 2006, p. 20, as cited in Dobrin 2008, p. 303)

Even if the issue of community involvement or lack thereof is resolved, a number of critically important issues remain. For example, involvement in indigenous communities is founded on a philosophical assumption that the notions of language, language proficiency, etc., between even Western-trained linguists are identical to those of the local indigenous communities. Yet as Makoni and Severo (2015) argue, "language" may be understood as singing traditional and religious indigenous songs to carry local cultural meanings that are not comprehensible to those who do not belong to the local indigenous communities. In such situations, efforts to harmonize orthographies may not necessarily result in preservation of the communities' cultural practices because they tend to override existing forms of writing.

Interest in promotion of indigenous languages that entails complex harmonization of dialects does not necessarily result in protection of indigenous cultures and may fail to appreciate the complex ways that communities use language practices and resist appropriation of new ways of discourse practices to protect their indigenous practices. This creates a conundrum for scholars because, while the intervention may be motivated by desires to protect or enhance the communities' capabilities to function in contemporary societies, indigenous communities may view their resistance to exactly the same projects, which are proposed for their advancement, as depriving them of a sense of self-preservation!

\section{Descriptions of articles in the issue}

This special issue is made up of five articles, excluding this introductory essay. The articles range from an analysis of theoretical issues relating to harmonization in Africa to perspectives about harmonization from outside Africa, in this case China. In the first article in this collection, Heugh writes on the many different ways in which linguists in southern Africa have written about harmonization. Her paper is unique insofar as it gives insights into the nature of the debates among linguists on issues relating to harmonization. Heugh's paper is followed by Banda's that describes the nature of harmonization projects in cross-border languages. He uses harmonization as a framework on which regional language and cross-border language policies could be grounded. His main focus is on southern Africa, but given the pervasive nature of cross-border languages, Banda's contribution is relevant to many geographical regions in East, West, and North Africa. Chebanne's paper is interesting as it tries to both focus on a specific group, the Khoi-San, whose 
work might not be very well known in many parts of the world and to illustrate the extent to which harmonization may facilitate local development of the Khoi-San communities. The final article by Wang, Juffermans, and $\mathrm{Du}$ is on Chinese perspectives on harmonization. This paper explores the ways in which harmonization is framed culturally and used as a political instrument of power by the Chinese government. The authors, however, finally demonstrate the degree to which the Chinese may deploy and undermine the policing powers of the Chinese government through the use of the Internet.

Acknowledgments I'd like to express my sincere thanks to Kaushalya Perera who managed and successfully administered the project.

\section{References}

Abdelhay, B., Makoni, B., \& Makoni, S. (2013). A very "oily" sociolinguistics of the "New Sudan": Old wine in new bottles. In N. Kamwangamalu, R. Baldauf, \& R. Kaplan (Eds.), Language planning in Africa: Cameroon, Sudan, and Zimbabwe. London: Routledge.

Dobrin, L. (2008). From linguistic elicitation to eliciting the linguist: Lessons in community empowerment from Melanesia. Language, 28(2), 300-325.

Doke, C. (1931). Report on the unification of the Shona dialects: Carried out under the auspices of the Government of Southern Rhodesia, presented to the Legislative Assembly. Southern Rhodesia: Mercury Press.

Makoni, S., \& Severo. (2015). Lusitanization and Bakhtinian perspectives on the role of Portuguese in Angola and East Timor. Journal of multilingual and Multicultural Development, 36(2), 151-162.

Miner, E. (2003). The development of Nuer linguistics. Retrieved from http://www.dlib.indiana.edu/ collections/nuer/edward/linguistics.html

Nhlapo, J. (1953, August). The problem of many tongues. Liberation, 4.

Nhlapo, J. (n.d.). Jacob N. Nhlapo. Retrieved from http://pzacad.pitzer.edu/NAM/newafrre/writers/ nhlapo/nhlapoS.htm

Prah, K. (2008). Africa in transformation: Political economic transformation and socio-political responses in Africa (vol. 2). Codesria: Organization for Social Sciences in East and Southern Africa.

Raboroko, P. (1953, September). The linguistic revolution. Liberation, 5.

Sinfree Makoni teaches in the department of Applied Linguistics and Program in African Studies at Penn State University, USA. He holds a PhD in Applied Linguistics from Edinburgh University. His main research interests are at the intersection of language policy with health, philosophies of language and security. He has published in a number of journals which include, Current Issues in Language Policy, Journal of Multilingual and Multicultural Development. 